\title{
Efficacy of endoscopic balloon dilation in Iranian pediatric patients with esophageal stricture
}

\author{
Mitra AHMADI ${ }^{1}$, Mohammad MANZARI-TAVAKOLI ${ }^{1}$, Hazhir JAVAHERIZADEH ${ }^{1,2}$, Mehran HAKIMZADEH ${ }^{1}$, \\ Mohammadreza MIRKARIMI ${ }^{3}$ and Asaad SHARHANI ${ }^{4}$
}

\begin{abstract}
Background - Esophageal stenosis (ES) in children is a fixed intrinsic narrowing of the esophagus due to numerous aetiologies. Objective - This study aimed to determine the clinical and nutritional impacts of endoscopic balloon dilation (EBD) in Iranian children with an esophageal stricture. Methods - This retrospective study, pediatric patients (aged <18 years) who underwent EBD for esophageal stricture from April 2015 until March 2020 in Abuzar Children's Hospital (Ahvaz, Iran) were enrolled in the study. Outcome parameters were the frequency of dilations, nutritional status, complications, and clinical success rates. EBD was used in children with radiologic evidence of esophageal stenosis. The nutritional status was evaluated by weight-for-age (z-score). Clinical success was considered as no necessity of EBD for a minimum of one year and/or increasing interval among dilation and the frequency of EBD was less than four times per year. Results - A total of 53 cases (mean age, $4.72 \pm 3.38$ years) were enrolled. There were $25(47.2 \%)$ females and $28(52.8 \%)$ males. During follow-up, a total of 331 EBD sessions were performed, with an average of 6.24 sessions per patient. There was one case of perforation and one case of mediastinitis, while there was no other complication or mortality. The clinical success rate of EBD therapy was $62.3 \%$ (33/53). The mean standard deviation z-score weight-for-age of patients before and after endoscopic dilation was 2.78 (2.41) and 1.18 (1.87), respectively. The $t$-test showed a significant difference between the weights-for-age (z-score) before and after endoscopic dilation. The majority of the patients had raised weight-for-age (z-score) after EBD treatment. Conclusion - EBD attained a good clinical success rate and nutritional improvement in children with an esophageal stricture.
\end{abstract}

Keywords - Endoscopic balloon dilation; esophageal stenosis; esophageal stricture; esophagus.

\section{INTRODUCTION}

Esophageal strictures in pediatric patients have several causes such as eosinophilic esophagitis, esophageal atresia, congenital anomalies, gastro-esophageal reflux disease, inflammatory disorders, and caustic ingestion ${ }^{(1-3)}$. The occurrence of diverse etiologies differs between studies. In developing countries, caustic injuries are more common ${ }^{(4,5)}$. The rate of esophageal stricture following caustic ingestion was $20 \%$ in a Honar et al. study ${ }^{(6)}$. It is a severe problem that leads to high morbidity associated with high aspiration risk, failure to thrive, and dysphagia ${ }^{(7)}$. Failure to thrive is the most significant concern of this clinical condition, as leads to an impaired oral intake ${ }^{(8)}$. This makes the cure of this severe condition critical.

Besides the outdated procedures, surgical revision, and bougienage, presently esophageal dilation with a balloon catheter is progressively utilized as a treatment modality in esophageal strictures ${ }^{(9)}$. Meanwhile, balloon dilation has been utilized commonly due to its theoretical benefits and safety, numerous studies started to cope with reasonable and long-term outcomes in pediatric patients. Nevertheless, there is no common consent on some parts of the technique, such as the optimal size of the balloon, intervals between dilations, or other methodological details ${ }^{(7)}$. In pediatric patients, balloon dilation (BD) is related to fewer dilation sessions and complication rates compared with bougienage ${ }^{(10)}$. In the study by Raboei et al., esophageal balloon dilation had the lower complication rate compared to savary dilations ${ }^{(11)}$.

The objective of esophageal dilation in patients with esophageal stricture is a clinical success or attaining adequate food intake. The majority of data regarding esophageal dilation are considered successful treatment due to the raised time among dilations and raised tolerance of food intake while assessment of nutritional status has seldom been reported. This present study aimed to evaluate the efficacy and long-term consequences of endoscopic balloon dilation (EBD) on the clinical and nutritional outcomes in children with an esophageal stricture.

\section{METHODS}

In this retrospective study, patients (aged less than 18 years) who underwent therapy with EBD for esophageal stricture from April 2015 until March 2020 in Abuzar Children's Hospital (Ahvaz, Iran) were enrolled in the study. Children's data were collected from the medical records. Patients entered the study at least one year after the first dilation. The children undertook barium esophagography and/or endoscopy to recognize the stricture and its site before EBD.

${ }^{1}$ Department of Pediatric Gastroenterology, Abuzar Children's Hospital, Ahvaz Jundishapur University of Medical Sciences, Ahvaz, Iran. ${ }^{2}$ Alimentary Tract Research Center, Clinical Sciences Research Institute, Ahvaz Jundishapur University of Medical Sciences, Ahvaz, Iran. ${ }^{3}$ Department of Pediatric Pulmonology, Abuzar Children's Hospital, Ahvaz Jundishapur University of Medical Sciences, Ahvaz, Iran. ${ }^{4}$ Department of Epidemiology and Biostatistics, School of public health, Ahvaz Jundishapur University of Medical Sciences, Ahvaz, Iran.

Corresponding author: Hazhir Javaherizadeh. E-mail: hazhirja@yahoo.com 
The author's contraindications in this study for EBD incorporated recent perforation, malignant illness of the esophagus, recent upper gastrointestinal surgery, severe cardiorespiratory disease, un-correctable coagulopathy, and instability of vital signs. Anticoagulants had to be withdrawn and coagulopathy modified before dilation.

EBD was implemented cautiously on children under general sedation taking midazolam with serious checking of vital signs; at least 6 hours before EBD, the patients had to have fasted.

Pediatric endoscopy was primarily utilized to evaluate stricture. A guidewire was pass through the stricture to assess the patency and size of it. In addition, a balloon catheter was located through the stricture, which was dilated by water inflation to apply linear pressure on the stricture. The precise placing of the balloon was accepted when it displayed a "waist" as it was centered through the stricture. Manual inflation (held for $30 \mathrm{~s}$ ) was implemented until the waist was eliminated. Each session of balloon dilation was three 30 seconds totally 90 seconds. Endo-flex balloon dilator (Voerde, Germany) was used for the treatment of oesophageal strictures. Pentax endoscope EG-2790k (Tokyo, Japan) was used in our unit for the treatment. The fluoroscopic method was not used in our setting. We used $\mathrm{x}$-ray 6 hour after esophageal dilation to evaluate perforation not identified during procedure. Patients were observed 24 hours after esophageal dilation.

The goal of EBD was to eliminate the stricture by full development of the waist of the balloon or to upsurge the esophageal diameter, thus permitting the endoscope to go over the stricture. The progress of ingestion ability (dysphagia scale) and nutritional status were used to evaluate the therapeutic efficacy of EBD.

The nutritional status of the patients was evaluated before and after EBD. The nutritional parameter measured was weightfor-age (z-score). Weight-for-age below -3 was considered severely underweight. Weight-for-age below -2 was considered underweight. Weight-for-age above 2 was considered overweight. Outcome parameters were the overall dilations, nutritional status, clinical success rates on EBD, and procedural complications. Furthermore, correlations of the site of the esophageal stricture with the clinical success rate were also assessed. Clinical success after EBD treatment was considered as having no requisite for EBD for at least one year or raising interval among EBD procedures and less than four EBD sessions each year. The clinical failure after EBD treatment was considered as a requirement for EBD for above one year or surgical intervention or enteral nutrition by gastrostomy. In addition, an improvement in nutritional status was considered as the attainment of an increase of weight-for-age (z-score).

The analyzed clinical were gender, clinical symptoms at presentation, age at diagnosis, nutritional status (z-score for body weight), management, sites (single or multiple) location (upper, middle, or lower), and procedural complications.

\section{Statistical analysis}

Data analysis was done using SPSS version 25. Descriptive statistics comprising means, range, percentage, and standard deviation were utilized to describe demographic information. Normality of data and homogeneity of variances was assessed by KolmogorovSmirnov and Leven test, respectively. Continuous variables were expressed as mean \pm standard deviation. Status changes were also analyzed by Student's $t$-test. Pearson's correlation analysis was used to determine the correlation between two groups. The chi-square test and the Wilcoxon test also were used. $P<0.05$ was considered to indicate statistical significance.

\section{Ethics statement}

Ethical approval was given by the Medical Ethics Committee of Ahvaz Jundishapur University of Medical Sciences, reference number (No: IR.AJUMS.REC.1398.803). All collected data were kept confidential without any imposed extra cost on the parents.

\section{Limitation}

Limited sample size and single-center study. We could not analyze some correlations due to the lack of some contrast studies.

\section{RESULTS}

A total documents of 53 patients with diagnosis of esophageal strictures were reviewed and the following results were obtained. The patients were $25(47.2 \%)$ females and $28(52.8 \%)$ were males. Ages of the patients ranged from 1 to 13 years with a mean age of $4.72 \pm 3.38$ years. Among patients, $32(60.4 \%)$ had esophageal atresia, $7(13.2 \%)$ had idiopathic esophageal strictures (IES), 5 $(9.4 \%)$ achalasia, $4(7.5 \%)$ patients with epidermolysis bullosa (EB), $2(3.8 \%)$ patients with gastroesophageal reflux disease (GERD), 2 $(3.8 \%)$ people suffering from strictures due to ingestion of corrosive substances), and one person with secondary esophageal strictures due to diaphragmatic hernia repair surgery (TABLE 1).

Correlation between aetiologies of esophageal strictures and clinical success of EBD therapy Among patients, 32 (60.4\%) had esophageal atresia, $7(13.2 \%)$ had IES, $5(9.4 \%)$ achalasia, $4(7.5 \%)$ patients with EB, $2(3.8 \%)$ patients with GERD, $2(3.8 \%)$ people suffering from strictures due to ingestion of corrosive substances), and one person with secondary esophageal strictures due to diaphragmatic hernia repair surgery (TABLE 2). There was no significant correlation between aetiologies of esophageal strictures and clinical success of EBD therapy among subjects using the chi-square test $\left(\mathrm{X}^{2}\right)\left(P=0.749\right.$ and $\left.\mathrm{X}^{2}=3.462\right)(\mathrm{TABLE} 2)$.

TABLE 1. Frequency of etiologies of esophageal stricture among patients $(n=53)$.

\begin{tabular}{lcc}
\hline $\begin{array}{l}\text { Etiologies of esophageal } \\
\text { stricture }\end{array}$ & $\begin{array}{c}\text { Number of } \\
\text { patients(n) }\end{array}$ & $\%$ \\
\hline Esophageal atresia & 32 & $60.4 \%$ \\
$\begin{array}{l}\text { Idiopathic esophageal } \\
\text { stenosis }\end{array}$ & 7 & $13.2 \%$ \\
$\begin{array}{l}\text { Achalasia } \\
\text { Epidermolysis bullosa }\end{array}$ & 5 & $9.4 \%$ \\
$\begin{array}{l}\text { GERD } \\
\begin{array}{l}\text { Ingestion of corrosive } \\
\text { substances }\end{array}\end{array}$ & 2 & $7.5 \%$ \\
$\begin{array}{l}\text { Diaphragmatic hernia } \\
\text { repair }\end{array}$ & 2 & $3.8 \%$ \\
Total & 1 & $1.9 \%$ \\
\hline
\end{tabular}

GERD: gastroesophageal reflux disease. 
TABLE 2. Frequency of clinical success of endoscopic balloon dilation therapy based on etiologies of esophageal stricture among subjects $(n=53)$.

\begin{tabular}{lccc}
\hline $\begin{array}{l}\text { Etiologies of esophageal } \\
\text { stricture }\end{array}$ & $\begin{array}{c}\text { Clinical } \\
\text { success } \\
\mathbf{n}(\%)\end{array}$ & $\begin{array}{c}\text { Clinical } \\
\text { failure } \\
\mathbf{n}(\%)\end{array}$ & Total \\
\hline Esophageal atresia & $\begin{array}{c}18 \\
(56.3 \%)\end{array}$ & $\begin{array}{c}14 \\
(43.8 \%)\end{array}$ & 32 \\
Idiopathic esophageal stenosis & $4(57.1 \%)$ & $3(42.9 \%)$ & 7 \\
Achalasia & $4(80 \%)$ & $1(20 \%)$ & 5 \\
Epidermolysis bullosa & $3(75 \%)$ & $1(25 \%)$ & 4 \\
GERD & $1(50 \%)$ & $1(50 \%)$ & 2 \\
Ingestion of corrosive substances & $1(50 \%)$ & $1(50 \%)$ & 2 \\
Diaphragmatic hernia repair & $1(50 \%)$ & 0 & 1 \\
\hline
\end{tabular}

GERD: gastroesophageal reflux disease.

\section{Comparison of weight-for-age (z-score) before and after} endoscopic dilation (TABLE 3)

The mean standard deviation z-score weight-for-age of patients before and after endoscopic dilation was 2.78 (2.41), 1.18 (1.87) respectively. The independent $t$-test showed a significant difference between the weight- for-age (z-score) of patients before and after endoscopic dilation.

Thirty-three $(62.3 \%)$ children achieved clinical success and 20 $(37.7 \%)$ patients experienced clinical failure (TABLE 4). In this study, a total of 331 sessions of balloon dilation were performed in 53 patients with esophageal stricture and mean session of EBD was 6.24 per patient. There was one case of perforation and one case of mediastinitis, while there was no other complication or mortality.

\section{Correlation between clinical success of EBD therapy and site of esophageal stricture}

Among the 53 patients, stricture at the upper third of the esophagus was seen in $16(30.2 \%)$ patients, in the middle third in $20(37.7 \%)$, and in the lower third in $12(22.6 \%)$ patients. $5(9.4 \%)$ patients had stricture at multiple sites (TABLE 5). There was no significant correlation between the site of esophageal strictures and clinical success of EBD therapy among patients using the chi-square test $\left(\mathrm{X}^{2}\right)\left(P=0.341\right.$ and $\left.\mathrm{X}^{2}=3.346\right)($ TABLE 6$)$.

\section{Correlation between clinical success of EBD therapy and gender of patients}

Of 25 female cases, $15(60 \%)$ showed successful EBD therapy. Of 28 male cases, $18(64.3 \%)$ had successful EBD therapy. There was no significant correlation between patients gender and clinical success using the chi-square test $\left(P=0.748\right.$ and $\left.X^{2}=0.103\right)$.
TABLE 4. Frequency of Clinical success of endoscopic balloon dilation therapy among patients $(n=53)$.

\begin{tabular}{lcc}
\hline Clinical achievement & $\mathrm{n}$ & $\%$ \\
\hline Clinical success & 33 & $62.3 \%$ \\
Clinical failure & 20 & $37.7 \%$ \\
\hline
\end{tabular}

TABLE 5. Frequency of sites of esophageal stricture among subjects $(\mathrm{n}=53)$.

\begin{tabular}{lcc} 
Site of esophageal stricture & Number of patients(n) & $\%$ \\
\hline Upper esophagus & 16 & $30.2 \%$ \\
Middle esophagus & 20 & $37.7 \%$ \\
lower esophagus & 12 & $22.6 \%$ \\
Multiple sites & 5 & $9.4 \%$ \\
Total & 53 & $100 \%$
\end{tabular}

TABLE 6. Frequency of clinical success of endoscopic balloon dilation therapy based on the site of esophageal stricture $(n=53)$.

\begin{tabular}{lccc}
\hline $\begin{array}{l}\text { Site of esophageal } \\
\text { stricture }\end{array}$ & $\begin{array}{c}\text { Clinical success } \\
\text { n (\%) }\end{array}$ & $\begin{array}{c}\text { Clinical failure } \\
\text { n (\%) }\end{array}$ & Total \\
\hline Upper esophagus & $8(50 \%)$ & $8(50 \%)$ & 16 \\
Middle esophagus & $12(60 \%)$ & $8(40 \%)$ & 20 \\
lower esophagus & $10(83.3 \%)$ & $2(16.7 \%)$ & 12 \\
Multiple sites & $3(60 \%)$ & $2(40 \%)$ & 5 \\
\hline
\end{tabular}

\section{Correlation between the clinical success of EBD therapy and first dilation among patients}

The chances of clinical success increased by 1.004 times with each year of age using the chi-square test but it was not significant $(P=0.668)$.

\section{DISCUSSION}

The findings of this present study revealed that EBD treatment assisted to get a better enhancement in nutritional status (weightfor-age) in the majority of the patients. This study indicates that EBD has a good clinical impact on esophageal stricture for nutritional support. We could not find any significant correlations of mean age, sites of strictures, gender, aetiologies, and sites of the stricture with clinical success of EBD therapy. Among, 53 documents of children which were reviewed, more than half of patients were males and the majority of patients $(60.4 \%)$ had esophageal atresia followed by $13.2 \%$ who had IES.

TABLE 3. Comparison of weight for age (z-score) before and after endoscopic dilation among patients.

\begin{tabular}{lcccc}
\hline Weight for age (z-score) & Mean & Standard deviation & Minimum & Maximum \\
\hline Before dilation & -2.87 & 2.41 & -8.38 & 1.60 \\
After dilation & -1.18 & 1.87 & -7.00 & 3.50 \\
\hline
\end{tabular}


Esophageal stricture is a critical problem that decrease the quality of life of patients. It's main and common complication is failure to thrive due to impaired food intake ${ }^{(10)}$. Chronic malnutrition and underweight was reported among $66.6 \%$ of children with esophageal stricture ${ }^{(12)}$. The $t$-test showed a significant difference between the weight-for-age (z-score) of patients before and after endoscopic dilation. EBD therapy helped to achieve a greater improvement in nutritional status (weight-for-age) in the majority of the patients similar to the study, which was conducted in Taiwan $^{(13)}$. Underweight was frequent among children with repaired esophageal atresia ${ }^{(14)}$. In the current study, weight-for-age $z$ score was improved following EBD. In another study among 50 cases with $268 \mathrm{EBD}$ session, weight-for-age $\mathrm{z}$ score showed increment in all cases ${ }^{(13)}$. Nutritional outcome was improved following EBD therapy ${ }^{(11)}$. The findings of the mentioned studies were similar in terms of improvement in nutritional status following EBD.

The present study found that balloon dilation had a good clinical success rate $(62.3 \%)$ while in another similar studies in Taiwan ${ }^{(13)}$ the rate was $72 \%$ and in Korea $64 \%$ of clinical success rate of EBD treatment was in corrosive injury ${ }^{(15)}$.

Esophageal perforation is a potential serious complication in patients with esophageal strictures ${ }^{(16)}$. The perforation of EBD in this study was one case 331 EBD session while another study in China $^{(16)}$ reported a rate of esophageal perforation of $1.5 \%$ (4 of 260 EBD sessions) in their sessions as well as in another study in Taiwan $^{(13)}$ that the overall perforation happened in $5(10 \%)$ children and 7 of the $268(2.6 \%)$ sessions. In the study by Geng et al., among 43 patients, 168 sessions of esophageal dilation were done. Among 168 sessions, seven esophageal perforations occurred in six patients ${ }^{(17)}$. As seen above, the rate of esophageal perforation in our study was lower than in the previous study. Etiology of esophageal strictures and endoscopist experiences may affect the frequency of esophageal perforations following EBD.

A total of $16(30.2 \%)$ patients had upper esophageal stricture, $20(37.7 \%)$ patients had middle esophageal stricture, and $12(22.6 \%)$ patients the lower esophageal stricture, and $5(9.4 \%)$ patients had multiple strictures. In contrast, in another study from Taiwan, stricture at the upper, middle, and lower third of the oesophagus were seen in $15(30 \%)$ patients, $11(22 \%), 17(34 \%)$ patients, respectively ${ }^{(13)}$ was reported among 50 patients.

A total of 331 sessions of balloon dilation were carried out and the mean session of EBD was 6.24 per patient. The number of EBDs was higher than the mean five sessions per patient in another study which was conducted in Turkey ${ }^{(7)}$. Earlier studies stated average intervals of 2-4 weeks among dilation sessions to get a complete clinical response ${ }^{(16,18)}$. The differences in time intervals depend on the initial stricture size, clinical response to the previous session, and stricture resistance to dilation ${ }^{(19)}$. Currently, there is no agreement on the ideal procedure of endoscopic dilation (time interval between sessions, frequency of sessions, and targeted lumen diameter). The rate of dilation and time interval between sessions depends mainly on the impacts of the earlier dilation session and the degree of symptomatic improvement $t^{(19)}$.

In the current study, there was no difference between site of stricture in terms of clinical success. But in another study, lower stricture had the highest clinical success ${ }^{(11)}$. This difference may be due to different sample size, number of esophageal dilation, and etiology.

In this study, there was no mortality but two cases of complications. Recently, balloon dilation has been implemented frequently in the cure of esophageal strictures, with a high success rate of $76-100 \% 0^{(7)}$. In the current study, the weight status differed markedly before and after endoscopic dilation. Our findings indicated that EBD therapy has impacts on nutritional support. The only disadvantage is that a balloon is single-use, therefore it is more expensive than a Savary ${ }^{(20)}$. In the study by Al Sarkhy et al., on 43 children with esophageal stricture, endoscopic is a safe and effective intervention by an experienced hand ${ }^{(21)}$. In another study by Bawasir et al., the complication of esophageal dilation are not common and open surgery is not frequently required ${ }^{(22)}$. In the recent retrospective study on 64 children with repaired esophageal atresia, number; diameter; and length of strictures were the most important predictive factors of the effectiveness of $\mathrm{EBD}^{(23)}$. In the study by Osuga et al., in 14 children with esophageal strictures, they found EBD is a safe modality for the treatment of esophageal stricture in children ${ }^{(24)}$. In the study by Ten Kate et al. they found large variations in management of strictures in the children with esophageal atresia due to lack of current consensus ${ }^{(25)}$.

The current study had some limitations. First, it was a retrospective study with a small sample size and there were differences in the time of beginning the EBD therapy in patients with different underlying illnesses. Second, to evaluate nutritional status, we tried to use Z-scores for all however, some patients did not have weight records. Third, we did not consider the height of the children thus body mass index z-score and the weight-for-height index did not evaluate.

\section{CONCLUSION}

In conclusion, endoscopic dilation is a safe technique with low morbidity and mortality when used by an experienced pediatric gastroenterologist. EBD attained a good clinical success rate in paediatric patients with an oesophageal stricture.

\section{Orcid}

Mitra Ahmadi: 0000-0001-8215-9784.

Mohammad Manzari Tavakoli: 0000-0002-8862-6838.

Hazhir Javaherizadeh: 0000-0001-7898-4589.

Mehran Hakimzadeh: 0000-0002-3210-1776.

Mohammadreza Mirkarimi: 0000-0001-7617-1322.

Assad Sharhani: 0000-0001-9277-7447.

\section{Authors' contribution}

Ahmadi $\mathrm{M}$ and Manzari-Tavakoli M: conceptualised the study and drafted the initial study protocol. Ahmadi M, ManzariTavakoli M, Javaherizadeh H, Hakimzadeh M, Mirkarimi M and Sharhani A: participated in the design of the protocol. All authors critically reviewed the draft of the manuscript and approved the final version. 
Ahmadi M, Manzari-Tavakoli M, Javaherizadeh H, Hakimzadeh M, Mirkarimi M, Sharhani A. Eficácia da dilatação do balão endoscópico em pacientes pediátricos iranianos com estenose esofágica. Arq Gastroenterol. 2021;58(4):520-4.

RESUMO - Contexto - Estenose esofágica (EE) em crianças é um estreitamento intrínseco fixo do esôfago devido a inúmeras etiologias. Objetivo - Este estudo teve como objetivo determinar os impactos clínicos e nutricionais da dilatação do balão endoscópico (DBE) em crianças iranianas com restrição esofágica. Métodos - Foram inscritos neste estudo retrospectivo, pacientes pediátricos (com idade <18 anos) submetidos a DBE para restrição esofágica de abril de 2015 a março de 2020 no Hospital Infantil de Abuzar (Ahvaz, Irã). Os parâmetros de desfecho foram a frequência de dilatações, o estado nutricional, complicações e taxas de sucesso clínico. A DBE foi usada em crianças com evidência radiológica de estenose esofágica. O estado nutricional foi avaliado pelo peso-por-idade (escore z). O sucesso clínico foi considerado como não necessidade de DBE por um período mínimo de um ano e/ou aumento de intervalo entre dilatações e frequência inferior a quatro vezes por ano. Resultados - Foram incluídos 53 casos (média de idade, 4,72 $\pm 3,38$ anos). Eram 25 mulheres $(47,2 \%)$ e 28 homens (52,8\%). Durante o acompanhamento, foram realizadas 331 sessões de DBE, com média de 6,24 sessões por paciente. Houve um caso de perfuração e um caso de mediastinite, enquanto não houve outra complicação ou mortalidade. A taxa de sucesso clínico da terapia de DBE foi de 62,3\% (33/53). A média (escore z) peso-para-idade dos pacientes antes e depois da dilatação endoscópica foi de $2,78(2,41)$ e $1,18(1,87)$, respectivamente. O teste $t$ mostrou uma diferença significativa entre os pesos por idade (escore z) antes e depois da dilatação endoscópica. A maioria dos pacientes havia aumentado o peso por idade (escore z) após o tratamento com DBE. Conclusão - A

DBE atingiu boa taxa de sucesso clínico e melhora nutricional em crianças com restrição esofágica.

Palavras-chave - Dilatação endoscópica por balão, estenose esofágica, esôfago.

\section{REFERENCES}

1. Thomson M, Tringali A, Dumonceau J-M, Tavares M, Tabbers MM, Furlano R et al. Paediatric gastrointestinal endoscopy: European society for paediatric gastroenterology hepatology and nutrition and European society of gastrointestinal endoscopy guidelines. J Pediatr Gastroenterol Nutr. 2017;64:133-53.

2. Pearson EG, Downey EC, Barnhart DC, Scaife ER, Rollins MD, Black RE, et al. Reflux esophageal stricture-a review of 30 years' experience in children. J Pediatr Surg. 2010;45:2356-60.

3. Ghiselli A, Bizzarri B, Ferrari D, Manzali E, Gaiani F, Fornaroli F, et al. Endoscopic dilation in pediatric esophageal strictures: a literature review. Acta Biomed. 2018;89:27-32

4. Özdemir R, Bayrakci B, Teksam Ö, Yalçin B, Kale G. Thirty-three-year experience on childhood poisoning. Turk J Pediatr. 2012;54:251.

5. Urganci N, Usta M, Kalyoncu D, Demirel E. Corrosive substance ingestion in children. Indian J Pediatr. 2014;81:675-9.

6. Honar N, Haghighat M, Mahmoodi S, Javaherizadeh H, Kalvandi G, Salimi M. Caustic ingestion in children in south of Iran: Retrospective study from Shiraz-Iran. Rev Gastroenterol Peru. 2017;37:22-5

7. Cakmak M, Boybeyi O, Gollu G, Kucuk G, Bingol-Kologlu M, Yagmurlu A, et al. Endoscopic balloon dilatation of benign esophageal strictures in childhood a 15-year experience. Dis Esophagus. 2016;29:179-84.

8. Alessia G, Barbara B, Daniela F, Elisabetta M, Federica G, Fabiola F, et al Endoscopic dilation in pediatric esophageal strictures: a literature review. Acta Biomed. 2018;89:27.

9. Youn BJ, Kim WS, Cheon J-E, Kim W-Y, Shin S-M, Kim I-O, et al. Balloon dilatation for corrosive esophageal strictures in children: radiologic and clinical outcomes. Korean J Radiol. 2010;11:203-10.

10. Chang CF, Kuo S-P, Lin HC, Chuang CC, Tsai T-K, Wu SF, et al. Endoscopic balloon dilatation for esophageal strictures in children younger than 6 years: experience in a medical center. Pediatr Neonatol. 2011;52:196-202.

11. Raboei E, Alabdali A, Sayed MH, Yousef Y, Bawazir O, Alsaggaf A, et al. The Outcome of Pediatric Esophageal Strictures Managed with Endoscopic Balloon Dilation in Saudi Arabia. J Laparoendosc Adv Surg Tech A. 2021;31:210-5.

12. Sag E, Bahadir A, Imamoglu M, Sag S, Reis GP, Erduran E, et al. Acquired noncaustic esophageal strictures in children. Clin Exp Pediatr. 2020;63:447-50.

13. Chang CH, Chao HC, Kong MS, Chen SY, Chen CC, Lai MW. Clinical and nutritional outcome of pediatric esophageal stenosis with endoscopic balloon dilatation. Pediatr Neonatol. 2019;60:141-8.
14. Askarpour S, Peyvasteh M, Dashtyan M, Javaherizadeh H, Ahmadi M, AliSamir M. Incidence of malnutrition, esophageal stenosis and respiratory complications among children with repaired esophageal atresia. Arq Bras Cir Dig. 2020;33:e1486.

15. Doo E-Y, Shin J, Kim J, Song H-Y. Oesophageal strictures caused by the ingestion of corrosive agents: effectiveness of balloon dilatation in children. Clin Radiol. 2009;64:265-71.

16. Lan L, Wong K, Lin S, Sprigg A, Clarke S, Johnson P, et al. Endoscopic balloon dilatation of esophageal strictures in infants and children: 17 years' experience and a literature review. J Pediatr Surg. 2003;38:1712-5.

17. Geng LL, Liang CP, Chen PY, Wu Q, Yang M, Li HW, et al. Long-Term Outcomes of Caustic Esophageal Stricture with Endoscopic Balloon Dilatation in Chinese Children. Gastroenterol Res Pract. 2018;2018:8352756.

18. Alshammari J, Quesnel S, Pierrot S, Couloigner V. Endoscopic balloon dilatation of esophageal strictures in children. Int J Pediatr Otorhinolaryngol. 2011;75:1376-9.

19. Dall'Oglio L, Caldaro T, Foschia F, Faraci S, Di Abriola GF, Rea F, et al. Endoscopic management of esophageal stenosis in children: new and traditional treatments. World J Gastrointest Endosc. 2016;8:212.

20. Khanna S, Khanna S. Management of benign oesophageal strictures in children. Indian J Otolaryngol Head Neck Surg. 2008;60:218-22.

21. Al Sarkhy AA, Saeed A, Hamid YH, Al Asmi MM, Altokhais TI, Ullah AA, et al. Efficacy and safety of endoscopic dilatation in the management of esophageal strictures in children. Saudi Med J. 2018;39:787-91.

22. Bawazir O, Almaimani MO. Complications of esophageal strictures dilatation in children. A tertiary-center experience. Saudi Med J. 2020;41:720-5.

23. Dai DL, Zhang CX, Zou YG, Yang QH, Zou Y, Wen FQ. Predictors of outcomes of endoscopic balloon dilatation in strictures after esophageal atresia repair: A retrospective study. World J Gastroenterol. 2020;26:1080-7.

24. Osuga T, Ikura Y, Hasegawa K, Hirano S. Use of endoscopic balloon dilation for benign esophageal stenosis in children: our 11 year experience. Esophagus. 2018;15:47-51.

25. Ten Kate CA, Tambucci R, Vlot J, Spaander MCW, Gottrand F, Wijnen RMH, et al. An international survey on anastomotic stricture management after esophageal atresia repair: considerations and advisory statements. Surg Endosc. 2021;35:3653-61. 